\title{
La Configuración postmoderna del cuerpo humano
}

\author{
Conrad Vilanou \\ Universidad de Barcelona
}

No hay duda que una de las aportaciones historiográficas más recientes ha sido la recuperación del cuerpo, cosa lógica si tenemos en cuenta que ya fue uno de los temas incluidos por Jacques Le Goff y Pierre Nora en el libro Hacer la historia. Junto a una serie de nuevos problemas y enfoques, aquella obra -que data de comienzos de la década de los años setentaofrecía propuestas a modo de presentación de nuevos ámbitos de estudio. Tal situación favoreció la proliferación de obras individuales y colectivas que tenían por objeto el estudio histórico de la imagen del cuerpo humano, referidas especialmente al periodo que va de la Edad Media hasta la modernidad.

En realidad hacía tiempo que el descubrimiento del inconsciente había minado la confianza en los valores asertivos de la palabra, lo cual situó el cuerpo en el centro de los discursos. En aquella misma obra, Jacques Revel y
Jean-Pierre Peter destacaron la desmemoria del cuerpo, siendo - como es - el lugar del deseo porque, en última instancia, toda palabra es deseo, toda palabra viene del cuerpo por más que «toda palabra ordenada, reflexionada, institucionalizada, se emplea en negar el cuerpo». ${ }^{1}$

Desde una perspectiva histórica, es obvio que los imaginarios corporales han quedado sometidos a un universo de orden, ya sea bajo el peso del rigor moral o bien bajo la mirada de una aséptica objetividad científica. «El autocontrol físico ha casado perfectamente con el deseo de controlar los cuerpos de los demás para conseguir un mejor orden social y religioso-moral». ${ }^{2}$ Las diferentes formas de coerción física que tanto predicamento han tenido tradicionalmente en la educación han sido repetidamente olvidadas: "una historia de la educación que se centre con exclusividad en el logro de aptitudes como la de la lectura y la escritura olvidará una de las principales funciones de las escuelas pobres, de caridad o elementales en el pasado: la imposición, la obediencia física o la educación como proceso para doblegar a los niños". ${ }^{3}$

El cuerpo se ha adaptado, pues, a los usos, a las costumbres, a los vaivenes de la historia. Se puede decir que el cuerpo es el huésped silencioso de los signos de la cultura por lo que posee un alfabeto que es posible conocer y descodificar. Por consiguiente, el imaginario del cuerpo ha pasado por diversas transformaciones estando sometido, actualmente, a la lógica consumista. Con todo, nos hemos olvidado del cuerpo, de su memoria, o lo que es lo mismo, de sus evoluciones y de su presencia en el proceso histórico, circunstancia chocante cuando observamos que el cuerpo es la materialidad más contundente $\mathrm{y}$, a la vez, la realidad más inmediata de nuestra entidad psicofísica. 
En ocasiones, da la impresión como si se hubiese actuado un tanto peyorativamente negando a lo corporal su correspondiente lugar en la historia.

Situación paradójica la que se ha generado ya que si bien el cuerpo es un producto social se constata su ausencia en los discursos que, por contra, han destacado desde antiguo los valores ideológicos. La eliminación de los «lugares de la memoria» (y el cuerpo es uno de estos topos) deja a las sociedades desprotegidas e incapaces de renovar su vida cultural. Sin embargo, las llamadas del cuerpo son reclamos que se empezaron a oír a fines del siglo XIX. Ya Nietzsche denigró en el Zaratustra de los despreciadores del cuerpo. En cualquier caso, los planteamientos de la escuela de los Anuales y de la historia de las mentalidades, sin olvidar los aportes de la antropología, han potenciado el resurgir de la historia del cuerpo. Tanto ha sido así que lo corporal ocupa, finalmente, un lugar privilegiado en las diferentes maneras de hacer historia, planteándose incluso líneas de trabajo - como las que formuló Roy Porter en su momento - sobre el particular.

\section{LA CONSTRUCCIÓN \\ SOCIAL DEL CUERPO}

Si durante años la investigación histórica se ha caracterizado por el silencio del cuerpo, es evidente que en los últimos tiempos su temati- zación ha generado una importante bibliografía que aborda la cuestión desde diversas perspectivas. ${ }^{4}$ Gracias a este proceso el cuerpo humano ha dejado de ser objeto exclusivo de la biología para ser considerado también una construcción social y cultural. Por otra parte, la historia de las mujeres ha permitido asentar los principios teóricos que inspiran las modernas investigaciones sobre el cuerpo que, por norma, se ha construido bajo la mirada masculina en un imaginario social que ha tomado -como sucede en el cuadro de Munch La danza de la vida- distintas formas, a saber, la mujer blanca (asociada a la virginidad), la mujer roja (vinculada a la imagen de deseo masculino) y, por último, la mujer negra (reflejo de un otoño menopáusico en el que ha acostumbrado a habitar la histeria). ${ }^{5}$ Todo parece indicar que los trabajos sobre la historia del cuerpo de las mujeres han erosionado el mito del "eterno femenino" que ha asociado la mujer a la imagen de la fecundidad lunar. ${ }^{6}$ Se ha pasado de un modelo único - según el cual el cuerpo femenino no era más que una copia defectuosa del masculino - a una concepción diferenciada, es decir, a una visión del cuerpo de la mujer como algo distinto que se ha construido históricamente. ${ }^{7}$

Paralelamente a este proceso, el contexto postmoderno (con una cultura audiovisual e informatizada que ha permitido el desarrollo de la inge- niería genética) ha obligado a replantear una serie de posiciones. Es evidente que bajo los palimpsestos postmodernos se esconden imágenes y perfiles de concepciones anteriores, algunas de ellas inequívocamente modernas y vinculadas al discurrir histórico de las revoluciones científico-tecnológicas. El cuerpo ha sido presentado durante la modernidad a modo de máquina y motor, analogías que hoy - por las propias características de la cultura postindustrial - evolucionan y se configuran a través de otras imágenes y lenguajes que insisten, actualmente, en dos aspectos que aparecen ligados: la serialidad (repetición que, con las técnicas de clonación, va más allá de la simple hipótesis) y la representación del cuerpo favorecida por el desarrollo masivo de los medios audiovisuales, circunstancia que provoca la desaparición del aura que envolvía a los cuerpos humanos. ${ }^{8}$

Walter Benjamín - con su categoría estética del auradejó constancia de la nostalgia por aquellos momentos de la historia de la humanidad en los que la memoria del hombre no había sido todavía desvalijada. Los cuerpos seriados (fotografiados o filmados) quedan desprovistos de su aura, es decir, de la singularidad, originalidad y autenticidad que les otorgaba antiguamente una entidad propia. Cuando el cuerpo cae bajo la lógica de su reproducción técnica la figura hu- 
mana se despersonaliza, siendo substituida por el anonimato de la masa. Así se da paso a una serie de cuerpos sin atributos que no se pueden distinguir entre la multitud, proceso que culminó con los reportajes propagandísticos de la cineasta Leni Riefenstahl que bombardearon, durante el periodo nacionalsocialista, al mundo entero.

Sea como fuere, lo cierto es que la emergencia de una serie de novedades bibliográficas, de exposiciones artísticas, de ensayos plásticos, de renovaciones en el campo de la danza, confirman la actualidad de un cuerpo que, durante siglos, ha sido considerado como un auténtico tabú. Lo corporal siempre ha tenido, desde la irrupción de la filosofía pitagórica sistematizada por el platonismo, algo de demoníaco, de corrupto y, por consiguiente, de deleznable. Ya para Platón el cuerpo era la cárcel del alma, de manera que la tradición cultural occidental - al asumir buena parte de la herencia de la filosofía griega - ha situado lo corporal en un lugar secundario.

De ahí la importancia de estas nuevas formulaciones y experiencias que nos proponen - desde perspectivas y miradas plurales como corresponde a la sensibilidad postmoderna - ensayar nuevos discursos sobre el cuerpo. Sin embargo, conviene subrayar que el análisis deconstructivo ha visto en los cuerpos lugares de la manifestación del poder, esto es, de represión del deseo. Por su parte, la crítica freudomarxista puso de manifiesto algo que Foucault destacó profusamente: la existencia, a lo largo de la historia, de una serie de dispositivos disciplinares (suplicio, castigo, represión, prisión) que han actuado sobre el cuerpo humano. «El poder se ha introducido en el cuerpo, se encuentra expuesto en el cuerpo mismo». ${ }^{9}$

El dominio del cuerpo se ha manifestado en el control de la movilidad, de la manera de vestir, del peinado e, incluso, de la mirada de todos aquellos que - como los escolares y los soldados - han sido internados históricamente en diversas instituciones. Así se explica la continuidad de los ejercicios gimnásticos que, durante décadas, uniformizaron el discurso corporal desde la escuela hasta el cuartel: los cuerpos también se han supeditado a los engranajes institucionales.

La evolución de las formas corteses analizadas por Norbert Elias, así como la consolidación de la ortopedia a mediados del siglo XVIII, confirma la existencia de un discurso pedagógico-moral preocupado por el correcto crecimiento y posición del cuerpo según un modelo jerarquizado que tiene, en el árbol que crece rectamente, un ejemplo a seguir e imitar. ${ }^{10}$ En consecuencia, las desviaciones anatómicas fueron consideradas como algo curioso y heterodoxo: los siniestros monstruos humanos (desde fetos prematuros hasta personas con palmarias defor- maciones físicas) son, al fin de cuentas, testigos silenciosos de una fantasmagoría encarnada en unos cuerpos que, por su rareza, serán objeto de estudio en diferentes academias científicas. ${ }^{11}$

También a los cuerpos, al igual que al arte neoclásico que Winckelmann rehabilitó en pleno siglo XVIII, se les exige orden y mesura, esto es, una proporción que implica una estructura equilibrada y un desarrollo armónico según los cánones de un ideal de belleza de perfección que hunde sus raíces en el modelo del atleta griego. Nos hallamos, pues, ante la proliferación de unos cuerpos clásicos perfilados a imagen y semejanza de los ejemplos corporales procedentes de una Antigüedad mediatizada por la excelencia corporal lacedemonónica. Esta situación favoreció el ulterior desarrollo de la educación física bajo la impronta de una orientación claramente masculina que exalta la energía muscular en un contexto estético-moral que combina la fortaleza corporal con los deberes cívicopatrióticos. Parafraseando a Juvenal, podemos resumir la fórmula de Winckelmann en la expresión mens pulchra in corpore pulchro que, de alguna manera, fue asumida por los vientos neoclásicos que siguieron a la Revolución Francesa que propugnaba una restauración clásica. ${ }^{12}$

\section{EL MITO MECÁNICO}

Desde la época griega la 
pasión por los autómatas ha sido una de las grandes tentaciones de la humanidad. Es sabido que Homero y Apolonio describieron, cada uno por su lado, unos ingenios míticos que se movían por sí mismos y que servían vino y otras bebidas en las fiestas. Aristóteles, en su Política, justifica la esclavitud ante la carencia de máquinas automáticas: «Pues si cada uno de los instrumentos pudiera realizar por sí mismo su trabajo, cuando recibiera órdenes, o al preverlas, y como cuentan de las estatuas de Dédalo o de los trípodes de Hefesto, de los que dice el poeta que entraban por sí solos en la asamblea de dioses, de tal modo las lanzaderas tejieran por sí solas y los pelctros tocaran la cítara, para nada necesitarían ni los maestros de obras de sirvientes ni los amos de esclavos». ${ }^{13}$

Con la llegada de la modernidad, pareció que la vieja profecía mecánica podía convertirse en una realidad inmediata. Si la Antigüedad concibió la naturaleza como un gran animal, la modernidad bajo el influjo del modelo mecanicista (cartesiano-newtoniano) - consideró que la realidad natural tiene una estructura comparable al de una máquina, estando sus movimientos regidos por leyes causales. Por consiguiente, la imagen del cuerpo humano se articuló a través de la analogía entre el cuerpo y la máquina. Además, el racionalismo cartesiano consolidó la idea de cuerpo-máquina, generándose una nueva imagen biomecánica del cuerpo humano tal como se desprende del Tratado del hombre de Descartes. Gracias a este proceso, el hombre se despega de aquel mundo mágico regido por los astros y los signos del zodíaco que tanta influencia tuvo en las visiones animistas del Renacimiento. Desde este mismo momento (siglo XVII), todo puede explicarse apelando a los mecanismos de los miembros, visceras y músculos del cuerpo humano aunque la filosofía cartesiana - que recurre al funcionamiento mecánico del organismo animal para ilustrar el del hombre - mantiene el dualismo antropológico entre cuerpo y alma. ${ }^{14}$

Descartes es un ejemplo paradigmático de indudables repercusiones para la ulterior situación del cuerpo en la cultura occidental: la máquina humana cartesiana trata de despojarse de todo misterio y da paso a una nueva época de las relaciones entre el hombre y la naturaleza. Si antes el cuerpo constituía una cosa extraña e ignota, ahora la explicación científica lo reduce todo al estatuto de una simple máquina. Pronto se asiste - desde la visión matemática que introduce el paradigma científico moderno - a una geometrización del espacio y de los cuerpos que lo ocupan. Esta matematización del espacio y del movimiento se plasma primero en los manuales de esgrima de los siglos XVII y XVIII y, un poco más tarde, en los trata- dos gimnásticos del siglo XIX.

Es sabido que el mismo Descartes, que consideraba máquinas a los animales, construyó una novia artificial a la que llamó Francine que, al parecer, se perdió en el mar por la indignación de un capitán al encontrarla y considerarla un engendro diabólico. En cualquier caso, una y otra vez, se ha insistido en el error de Descartes. ¿Cuál fue ese error? Consumar la definitiva separación entre mente y cuerpo, entre res cogitans y res extensa, o lo que es lo mismo, suponer que las operaciones de la mente están separadas de la estructura y del funcionamiento del organismo biológico a pesar de que supeditó - a través de la glándula pineal - la res extensa a la res cogitans. ${ }^{15}$

Durante décadas, lo psíquico y lo biológico, lo intelectual y lo corporal, marcharon por caminos divergentes y separados. Entre la tradición humanístico-filosófica (Sócrates) y la médicobiológica (Hipócrates) se abrió un abismo casi insalvable, que sólo algunos médicos-filósofos del humanismo renacentista intentaron superar recurriendo, en más de una ocasión, a una filosofía natural, orgánica y global que -contraria a los principios de la física newtoniana- resurgirá con el modelo del desarrollo orgánico de Leibniz y, a la larga, con la naturphilosophie romántica, proceso que inspirará sistemas filosófico-peda- 
gógicos, de carácter teosófico, como el de Rudolf Steiner y su metodología Waldorf.

Para Leibniz reducir el hombre al modelo de la máquina equivale a limitarlo unilateralmente a la perspectiva externa de la sucesión de sus estados sin aprehender la unidad interna que determina su autodesarrollo. Según la Monadología leibniziana el cuerpo se presenta como un agregado orgánico de substancias indivisibles e incorruptibles: «cada cuerpo orgánico de un viviente es una Especie de Máquina divina o de Autómata Natural, que sobrepasa infinitamente a todos los Autómatas artificiales». La diferencia entre lo natural/orgánico y lo artificial/mecánico es clara porque «una máquina hecha por el arte del hombre no es una Máquina en cada una de sus partes». ${ }^{16}$

Tampoco hay que olvidar que, justamente, el rescate romántico de la naturaleza propició el desarrollo de determinadas prácticas físicas como el excursionismo y el montañismo a partir de la valoración positiva de la naturaleza que se presenta a pensadores, artistas y deportistas en medio de la exaltación de las fuerzas telúricas. Un miembro destacado de la generación literaria del 27 como Giménez Caballero exclama: «El alpinismo comenzó por originarse de una elucubración sentimental y pedagógica (¡Oh Rousseau!). No se concibe un griego yendo a buscar la divinidad en el infinito del Mont Blanc»». ${ }^{17}$
Sin embargo, el maqumismo (con su apología de la disciplina mecánica satirizada por Charlot en Tiempos Modernos) dejó su impronta en la corporalidad. La revolución tecnocientífica moderna se levanta sobre los cimientos de un mundo que será interpretado, siguiendo la tradición artesanal, a modo de una máquina que se refleja en la metáfora del reloj. Dios, a manera de gran ingeniero, ha construido el mundo con toda perfección, como si se tratara de una ajustada maquinaria de relojería. Las clásicas artes liberales ceden su hegemonía a las artes mecánicas que cobran especial relevancia durante el período que va del Renacimiento a la Ilustración. Los diseños voladores de Leonardo da Vinci anunciaron la llegada del «animal máquina». Los inventos de Julen Leroy (1686-1759) y Jacques Vaucanson (1709-1782) influyen sobre Julien de La Mettrie que, con su fisiología mecánica, consolidará una mitología mecánica, de talante materialista. No por casualidad, La Mettrie concluye su tratado de El hombre máquina señalando que «el hombre es una máquina, y que en todo el universo no existe más que una sola substancia diversamente modificada». ${ }^{18}$

Paralelamente a este proceso, las instalaciones de autómatas que funcionan al ritmo de la música florecen por doquier (especialmente en mansiones burguesas y aristocráticas), estableciéndose una nueva relación entre el hombre, la ciencia y la naturaleza.
La máquina deja de ser un enmascaramiento para convertirse en un símbolo del dominio del hombre sobre la naturaleza, más todavía si tenemos en cuenta que el mundo de los autómatas se emancipa pronto del ambiente cortesano en el que hasta entonces se había desenvuelto.

De esta forma, se divulga su conocimiento -que será utilizado en el siglo XIX con fines publicitarios- entre las clases populares: los autómatas pasan de ser juegos de corte o curiosidades de gabinete a representaciones teatrales y callejeras. El autómata, además de un ingenio mecánico, es igualmente un objeto estético y lúdico, apoderándose con el paso del tiempo del mundo de los juguetes. Los androides mecánicos plasman las ideas antropológicas que se sustentan en el modelo del hombre-máquina que funciona automáticamente al ritmo musical: a través de este proceso la imagen del hombre-máquina con su frío funcionamiento neutraliza el halo mágico y espiritual que, desde antiguo, había acompañado al cuerpo humano. ${ }^{19}$

Las máquinas empiezan a ser algo más que simples herramientas o distraídos pasatiempos ya que inciden directamente en los procesos económicos de producción a gran escala. Pero las críticas no se hacen esperar. Marchel Duchamp, con sus ready-made, se enfrenta a las máquinas siendo, por tanto, uno de los 
primeros en denunciar el carácter ruinoso de la tecnociencia. Los únicos mecanismos que apasionan a Duchamp serán los antimecanismos (los ready-made) cuyo funcionamiento insólito los anula como máquinas. ${ }^{20} \mathrm{Su}$ aparente sin sentido es sólo ficticio ya que poseen una inequívoca significación: son máquinas que destilan la crítica de sí mismas. Con sus simulacros de máquinas, Duchamp pretendía contribuir a la subversión irónica del mito futurista del hombremáquina, el centauro moderno que con la exaltación de la velocidad se transmuta en algo totémico.

Tras la hegemonía del reino animal, se impone la tiranía del mundo mecánico hasta el punto que el autor dramático Karel Capek introduce la palabra «robot» (término que en checo significa una especie de obrero esclavizado) en su obra R.U.R. (Rossum's Universal Robots) que data de 1920. ${ }^{21}$ Los cuerpos de los obreros y de las obreras son un simple engranaje, sometido al ritmo frenético de las técnicas de producción. Pero no acaba aquí la cosa porque al fin de cuentas, estos mismos cuerpos son los que aparecen en los documentales de las primeras décadas del siglo $\mathrm{XX}$, aquellos cuerpos que se estremecían entre el fango de las trincheras de la primera guerra mundial o bien aquellos otros cuerpos que marchaban hacia una muerte segura - el cuerpo es un topos donde el tiempo deja su huella
- en los campos de exterminio de la barbarie nacionalsocialista.

Pero el documentalismo fotográfico y cinematográfico ha permitido tener memoria de esa manipulación, de ese uso y abuso ejercido sobre unos cuerpos que desfilaban de una manera mecánica y automática, como si se tratasen de los resortes de una máquina bélica, expresión del irracionalismo y del totalitarismo. El último gran espectáculo nacionalsocialista antes del inicio de la segunda guerra mundial fue la celebración del 50 aniversario de Hitler, el 20 de abril de 1939. Un imponente desfile militar recorrió, durante cuatro horas, los diez kilómetros del eje Este-Oeste que atravesaba Berlín, una especie de via triumphalis, que servía de atalaya no sólo para demostrar la fuerza militar del Reich sino también para expresar, con toda su crudeza, la siniestra estética de la violencia y del horror.

\section{CUERPOS A MOTOR}

Después de consolidarse la imagen mecánica del cuerpo humano durante los siglos XVII al XIX, se asistió a su motorización. Pronto la hegemonía de la máquina y de los saberes mecánicos cedieron su protagonismo a un nuevo modelo que, sobre los cimientos de un mundo que era interpretado como máquina, halló en el motor su imagen preferida. A raíz de las reflexiones de Michel Serres, sur- gen dos metáforas bien diferenciadas. En primer lugar, la idea de máquina que corresponde al período clásico (desde el Renacimiento al siglo XIX) y que interpreta cuerpo y naturaleza como si fueran ellos mismos máquinas. Y posteriormente, a partir de la segunda mitad del siglo XIX se asiste a una «biologización» de la metáfora, a modo de símil de las máquinas a vapor que aparecen como si fueran organismos vivientes. $^{22}$

Así pues, se produce una identificación entre el cuerpo y la máquina de vapor, tal como confirma la atracción ejercida por las locomotoras que son comparadas con los caballos a galope. Después, esta identificación se realiza respecto al motor térmico que produce energía mecánica a partir de la combustión de la energía química. La imagen del motor va a insuflar a la máquina una nueva dimensión que, de acuerdo con la vanguardia futurista, exalta el movimiento y la velocidad. Además, todo se precipitó con la integración de las viejas técnicas y conocimientos en un modelo que encontró en el motor su artefacto prioritario, $\mathrm{y}$ en la química, el electromagnetismo y la termodinámica, sus principales disciplinas.

Las metáforas sobre el cuerpo y la naturaleza se construyen ahora a partir del paulatino agotamiento del clásico modelo mecanicista que deja las puertas abiertas a la instauración de un emer- 
gente modelo orgánico que encuentra en el relato del doctor Frankenstein una nueva versión del mito de la maternidad, si bien el monstruo inventado puede verse también como una representación simbólica de la tiranía de la maternidad sobre la mujer. En la novela de Mary W. Shelley la excelencia del saber químico -de la nueva química de Lavoisier- se pondrá al servicio de la «búsqueda de la piedra filosofal y el elixir de la vida». En cierto sentido, se vuelve a un modelo organicista-vitalista clásico (con sus resurrecciones renacentistas) en el que hay una organización del todo, semejante a un organismo vivo que funciona gracias a una motorización del cuerpo humano en el que las partes no se agregan como una mera «suma» sino como un todo de carácter vitalista.

Al fin de cuentas, el vitalismo - aquel élan vital reclamado por la filosofía de Bergson - confirma el hiato existente entre el árbol de la ciencia (de una ciencia abstracta, geométrica, racional y mecánica) del árbol de la vida, de una vida que - a través de Schopenhauer y Nietzschereivindica un lugar en el pensamiento del siglo XIX. Además, con los nuevos descubrimientos en geología y la aparición de la teoría darwiniana de la evolución, asistimos a una progresiva «biologización» metafórica de la tecnología: las máquinas se animan y los cuerpos se motorizan. En 1897 se inicia la construcción del motor Diesel. También en aquel mismo año, cuando las carreras del hipódromo estaban en su máximo apogeo, se patenta en Francia el caballo de gasolina: el drama del animal estriba en el éxito del hombre que ve en la imagen de las motocicletas y de los automóviles una poderosa y misteriosa fuerza que lo acerca a la mitología de los caballos alados. El hombre se convierte así en un auténtico centauro que, gracias a la motorización, domina - como las aves - las técnicas de vuelo y aterrizaje. Todo indica que el hombre ha tornado al totetismo: desea ser pájaro y pez, como si estuviera dotado de un poder sobrenatural. No es extraño, pues, que los primeros vuelos aéreos fuesen incluidos en los libros de los récords deportivos a modo de grandes proezas heroicas que tuvieron en los viajes transoceánicos, entre Europa y América, su mejor manifestación.

La imaginación del futurista - ahí está el Manifiesto de Marinetti- es analógica: las máquinas se metaforizan como animales. Si en un principio la modernidad fraguó la imagen del cuerpo como máquina, en las últimas décadas del siglo XIX se introduce, a partir de una nueva visión de la técnica, la metáfora del cuerpo a motor. En torno a 1900, la figura que domina y encubre esa correspondencia entre lo artificial y lo natural es la imagen omnipresente de la mujer que se erige en el principal signo mediador en- tre técnica y naturaleza. La imagen simbólica de la mujer - elevada a la categoría de diosa de un progreso motorizado - se convierte en "manifestación directa del élan vital, movimiento y pulsión originaria de esa vida que padece un raquitismo crónico y decadente a consecuencia del peso insostenible de una cotidianidad mecanizada y de un entorno artificial". ${ }^{23}$ Los carteles publicitarios de la época reflejan mujeres pilotando automóviles, embarcaciones náuticas o aeroplanos, de modo que la figura de la mujer se erige en el principal signo mediador entre la técnica y la naturaleza.

La imagen del cuerpo a motor corresponde históricamente con la época de la consolidación del deporte como fenómeno social que ha sido puesto en relación con un deseo, consciente o inconsciente, de prolongar la infancia. Al fin de cuentas, como manifestaron Holderlin y Nietzsche, siempre encontramos un niño en el interior de cada hombre. De ahí, pues, la recuperación de la dimensión lúdica de la vida humana que, desde una u otra perspectiva, reivindicarán Schiller, Claparéde, Guardini o Huizinga, proceso que ejerció una gran influencia antropológica y psicológica sobre la pedagogía y que cristalizó en el movimiento de la Escuela Nueva.

Las actividades físicas que durante el siglo XIX se habían circunscrito mayoritariamente 
al espacio cerrado de los gimnasios - muchos de ellos instalados en locales insalubres y con escasa ventilaciónpasan a desarrollarse al aire libre, proceso que adquiere una especial significación que se refleja de inmediato en el arte a través de la «poética de las energías». Es sabido que impresionistas como Manet y Degas se interesaron por las carreras hípicas, deporte típicamente inglés, que alcanzó gran popularidad en Francia. En el caso de Degas, la hípica fue uno de los pocos temas que pintaba al aire libre. Su cuadro «Caballos de carreras: el entrenamiento» (1894) demuestra que, olvidándose de los espectadores y del entorno del hipódromo, Degas concentra su atención en los jinetes y caballos pues éstas son las imágenes donde puede captar mejor la acción y el movimiento, aspectos que Marey intentó fijar a través de la cronofotografía.

El cuerpo humano, bajo la metáfora de la motorización, adquiere una dimensión dinámica, es decir, transmite fuerza (dynamis) y movimiento que los pintores estudian ávidamente. La serie de 46 dibujos expuesta por Umberto Boccioni entre marzo y junio de 1914, en la Galería Gonnelli de Florencia, así lo confirma. Naturalmente los deportistas (boxeadores, futbolistas, ciclistas) - es decir, modelos generalmente masculinos que transmiten salud y limpieza, mientras que lo femenino se relaciona a la enfermedad y suciedad- tras- lucen perfectamente esta imagen plástica de dinamismo que será asumida por los artistas de la vanguardia futurista que ven en el deporte un claro signo de modernidad. ${ }^{24}$

El deportista - desde el horizonte del cuerpo motornecesita consumir combustible bajo la forma de oxígeno. Los diferentes movimientos higienistas, el escultismo, el movimiento alemán de las aves errantes (Wandervögel), la promoción de los métodos naturales en la educación física (Hébert), promocionan el neonomadismo. El cuerpo a motor recurre, de nuevo, a la naturaleza, a fin de encontrar el aire puro para alimentar un cuerpo que necesita combustible. El petróleo que hace mover los motores es reemplazado en el caso humano por el oxígeno: el interés por el aumento de la capacidad torácica y la práctica de los ejercicios respiratorios al aire libre confirman esta tendencia que se introduce en las prácticas educativas con una finalidad médico-higiénica. La oxigenización del cuerpo humano favorece su fortalecimiento y, por tanto, constituye la mejor defensa contra una serie de enfermedades que se transmiten a través de los microbios que pululan por los ambientes cerrados.

Nos encontramos ante la exaltación del «plenairismo», es decir, la búsqueda de escenarios «au plein air». Se impone el retorno a la Madre Tierra y el contacto con las fuerzas telúricas de la natu- raleza. Así las nuevas corrientes expresionistas - rememorando aspectos de la pintura romántica- destacarán la importancia del paisaje playas, espacios naturales, etc. - en las que, en ocasiones, se detecta la presencia de figuras humanas que se introducen en el agua como reflejan las pinturas de Sorolla. Para combatir el neosedentarismo de la sociedad industrial nada mejor que volver a la naturaleza donde el aire nueva fuente energética del cuerpo humano - es puro y cristalino. La imagen cinematográfica de un Tarzán atlético - al fin de cuentas, ésa era la visión que pretendía transmitir Johnny Weismuller, campeón olímpico transmutado en semidiós del neonomadismo a partir de una novela del escritor norteamericano E. Rice Burroughs ${ }^{25}$ plasmaba de alguna manera esta visión idílica de un cuerpo a motor: en medio de la naturaleza africana Tarzán sólo contaba, además de su bondad natural que lo acercaba al "homme sauvage" de Rousseau, con la capacidad de sus pulmones, una especie de motor que sólo dependía del suministro de unas cuantas dosis de oxígeno. Todo ello favorecerá el desarrollo de la fuerza muscular, de manera que el cuerpo deja de ser robusto y pesado con lo que desaparece el culto a la fuerza que representaba el típico forzudo del circo. En consecuencia, el cuerpo se hará cada vez más esbelto.

Pero la imagen del cuerpo 
experimentó un vuelco radical después de la segunda guerra mundial. Las cámaras de fotografía de los reporteros de guerra difundieron un espeluznante mundo de terror. Nada fue igual después de 1945. La barbarie -con la destrucción sistemática y planificada de tantos cuerpos, de tantas vidas- adquiría una lúgubre faz humana: todo se reducía a materia anónima y mutilada. A partir de ese momento muchos artistas se preguntaron si era posible todavía representar la figura humana. La pintura de Francis Bacon, con sus cuerpos destrozados y reducidos plasmando el dolor, es una buena muestra de la desazón que se produjo en la conciencia de artistas e intelectuales. Incluso hubo artistas que, después de la guerra, rechazaron el ideal de belleza -ahí están las pinturas de Jean Dubuffetpara enfatizar, a modo de provocación, lo feo. El existencialismo con sus temas preferidos (el vacío, el sinsentido, el dolor, la náusea y la muerte) confirma que la vida humana se encamina hacia unos tiempos de estrechez que, necesariamente, provocan angustia. $\mathrm{Y}$ aunque después de la segunda conflagración mundial el escultor Alberto Giacometti prometió que sus esculturas no disminuirían un solo centímetro, sus figuras - que plasman la extrema fragilidad humanaadquirieron una extraordinaria delgadez. Ante tales representaciones, Sartre describió las esculturas de Gia- cometti como esbozos que se mueven siempre a medio camino entre el ser y la nada.

\section{DEL ROBOT AL CYBORG}

Paradójicamente, la guerra nos trajo también el despegue de la robótica, el aviso de la llegada de la era de los ordenadores, la digitalización de la información y el surgir de la sociedad del conocimiento. Es claro que los antecedentes de la cibercultura que tiene en Wiener a uno de sus fundadores más preclarosse encuentran en los estudios sobre automatización y control promovidos por la industria bélica durante la segunda guerra mundial. Pero el enfoque tecnocultural de la cibernética supera los estrictos límites de la ciencia afectando, también, aspectos antropológicos más allá incluso de la articulación de un incipiente homo digitalis: se asiste - en palabras de G. Colaizzi - al tránsito de la aldea global al circuito integrado, de manera que se anuncia la llegada de una nueva etapa postorgánica en la que los límites entre lo físico y lo no físico se difuminan. Después del descubrimiento de la cadena del ADN los organismos biológicos se entienden como textos codificados, y descodificados por la informática, la biología y la medicina. $^{26}$

El petróleo -fuente de energía de la modernidad- ha dado paso a nuevas energías -las derivadas de la infor- mática - que, entre otras virtudes, no contaminan, son inagotables y mucho más baratas. Por ello, cada vez se destaca con mayor énfasis el paso del sujeto biológico - según la imagen que descansa en la analogía entre cuerpo y motor- al cyborg, abreviatura de cybernetic organism, esto es, un ser híbrido, cibernético, resultado de la combinación de organismos o cuerpos con máquinas que toman forma en una serie de imágenes de la cinematografía de ciencia ficción a modo de Terminator, demiurgo encargado de preparar la invasión y el triunfo de los robots. Ante el ruido de la ciudad homogeneizada, el cyborg opone el "silbido intermitente de sus pilotos, la alerta de sus señales termoacústicas, el parpadeo de sus indicadores luminosos, intracorporales y neurofisiológicos, que le avisan de interacciones posibles en un nuevo paisaje sensorial". ${ }^{27}$

El cyborg es una figura metafórica acuñada por Haraway en 1985 - y desarrollada posteriormente - que presenta lo humano como una posibilidad virtual hasta el punto de constituir una nueva ontología postmoderna. ${ }^{28}$ Las máquinas y las nuevas tecnologías (ahí está la ingeniería genética a manera de un software humano) han convertido en algo ambiguo la diferencia entre lo natural y lo artificial, entre el hombre y la mujer, entre el cuerpo y la mente, entre el desarrollo orgánico y la planificación 
exterior, generándose así la viabilidad de una epistemología feminista en la que se cruzan las cuestiones de género, sexualidad y nuevas tecnologías. ${ }^{29}$

Hemos pasado del determinismo biológico a la manipulación genética, de la contingencia topográfica a la ubicuidad virtual, de la lógica de la representación a la simulación del clonado virtual, en fin, asistimos al tránsito del sujeto biológico al cyborg entendido como algo más que una posibilidad telemática que garantiza el intercambio de información entre las tecnologías informática, robótica y biológica. Con todo, la creación por Haraway del cyborg no propone descartar lo «real», sino, por contra, expandirlo, complicarlo, mostrar su construcción multívoca de capas múltiples que acaban con las distinciones, límites de la dominación.

Nos hallamos, pues, ante una nueva situación ya que lo virtual anuncia y escenifica la desaparición de la categoría de lugar. El éxtasis de un cyborg no está asociado a la capacidad de apreciación estética, ni vinculado al deseo o las emociones, sino a la conexión con el mayor número de redes posibles. El cyborg es el héroe de la interactividad digital de forma que los avances técnicos permiten la aparición de nuevos discursos corporales ya que los cuerpos se hacen nómadas, etéreos y volátiles. La virtualidad faculta todas las hibridaciones en- tre naturaleza y artificio, entre realidad y simulación. El sólo enunciado de una nueva corporeidad parece diluir los principios sobre los cuales se ha definido históricamente cada género. Si tradicionalmente el sexo biológico ha determinado la adscripción automática a su modelo cultural de referencia, ahora asistimos a un proceso a través del cual las identidades sexuales son cuestionadas abiertamente. De este modo, aparece el unisex y la industria de la moda se inclina cada vez más por la creación mediática de un patrón sexualmente equívoco, imponiéndose unos modelos indefinidos que acentúan más los rasgos comunes de los sexos que sus diferencias.

La cosa se agrava cuando pensamos que las mismas técnicas de reproducción permitirán una selección de la humanidad. Los sueños apocalípticos de la ciencia-ficción, con sus engendros mecánicos (androides, robots, terminators, replicantes, alienígenas), parecen estar más cerca que nunca. Aunque la idea del robot que nadie podrá distinguir de los seres humanos se encuentra ya en los orígenes del siglo $\mathrm{XX}$, lo cierto es que el pesimismo en torno a la sociedad del futuro se agudizó a lo largo del último siglo. Si Metrópolis de Fritz Lang (1926) -el sueño temido pero a la vez deseado de una sociedad mecanizada y robotizada- representaba un canto a la esperanza (al fin de cuentas eso es lo que trans- mitía el personaje femenino de María, si bien su réplica de laboratorio aconsejaba la revuelta), los replicantes de Blade Runner (1982) -Los Angeles, 2019- son réplicas humanas creadas por empresas de ingeniería genética. ${ }^{30}$

Para aquella fecha (2019), la metrópolis se habrá convertido en un lugar superpoblado, sucio y caótico. Entonces la ingeniería genética será una de las mayores industrias de la Tierra, suministrando seres humanos manufacturados genéticamente - los llamados replicantes - que son enviados a las colonias extraterrestres de una manera esclavizada. Por otra parte, los replicantes son reconocibles porque están faltos de una respuesta afectiva. Con todo, Blade Runner que retoca románticamente el desenlace pesimista de la novela de Philp K. Dick, nos ofrece una imagen decante y perversa de un futuro metropolitano que se presenta como el fin de una civilización que contrasta con el optimismo cinematográfico que va desde las películas futuristas de los años veinte hasta 2007, una odisea en el espacio.

\section{EL CUERPO Y LO VIRTUAL}

De la misma manera que Georges Orwell nos alertó sobre los peligros que podrían acechar a la humanidad en una fecha como la del año 1984, es claro que Blade Runner -con su sistema de reproducción en laboratorio al 
margen de las relaciones humanas- constituye una crítica hacia la sociedad contemporánea y un aviso sobre la posible ruina de nuestra civilización que así encuentra, en la hipotética cita del 2019, una seria advertencia. Hemos visto como el cuerpo, al compás del progreso de la sociedad industrial, permitió en primer lugar la analogía con la máquina automática, y más tarde, con el motor de explosión. Bajo la influencia de estas metáforas, el cuidado del cuerpo quedó sometido a la lógica productiva: había que ser fuerte para ser útil. Pero ahora, cuando estamos inmersos en un contexto postindustrial en el que cada vez es menos necesario el trabajo corporal, asistimos a una nueva visión del cuerpo, potenciada por los avances científico-técnicos, lo cual permite todo un mundo de posibilidades en el que se podrán proyectar muchos deseos. Así surgen esos cuerpos idealizados - plenos de belleza y perfección, sonrientes y siempre jóvenes- que pululan por los imaginarios publicitarios y que acaban provocando la desazón ante la constatación de nuestras propias limitaciones e imperfecciones corporales.

No hay duda que el cuerpo humano es ropos de la memoria personal, de una memoria passionis. La biografía de cada uno de nosotros deja sus huellas en el cuerpo que, de este modo, se convierte en testimonio de vida y, al unísono, de envejecimiento. Los rostros de los seres humanos - como bien han plasmado artistas y fotógrafos - dan cuenta y razón de esas penalidades y sufrimientos que, a través del transcurso del tiempo, dejan su impronta en nuestras facciones. ${ }^{31}$ Por ello a veces nos sentimos incómodos ante nuestra propia imagen porque no son muchos los que encuentran una autocomplacencia narcicista con su propio cuerpo. Igualmente pocos son los que se reconocen satisfactoriamente cuando se ven fotografiados o filmados. A menudo quisiéramos olvidar nuestro propio cuerpo (o como mínimo modificarlo y reformarlo) ya que se convierte en una angustiosa sombra que nos persigue constantemente. Finalmente, ese cuerpo causa nuestro propio malestar pues "la muerte, el sexo, la enfermedad, lo prohibido, nosotros mismos y sobre todo nuestras relaciones con nosotros mismos y con ese reflejo cambiante y repetido que es el otro, son nuestras obsesiones". ${ }^{32}$ Se produce, por tanto, una especie de esquizofrenia ya que nos sentimos - cual espíritu romántico - escindidos entre la realidad y el deseo, el deseo de una inmortalidad que encuentra en el Fausto goethiano, además de un antecedente histórico, un inequívoco punto de referencia: todos deseamos - de una u otra forma - ser imperecederos.

En realidad, el cuerpo es el lugar donde trabajamos nuestros miedos y nuestros deseos. Gracias al fitness, a la cosmética y a la cirugía plástica, los cuerpos pueden cambiar, esto es, transformarse y modificarse. La abstinencia más allá de su significación como pureza corporal- se convierte también en una buena estrategia, en una especie de no deseo. Ese es, justamente, el significado de la anorexia, palabra formada por la partícula an de carácter privativo y el verbo orego, desear. La insatisfacción provoca, al fin de cuentas, ese nodeseo respecto nuestros propios cuerpos que, por lo general, no se adecúan a los cánones establecidos por una cultura visual - una cultura de simulacro, en palabras de Baudrillard - que enmascara la vida humana con una serie de representaciones que, a modo de redes, acaban por colonizar el existir humano. Así la ontología corporal encuentra su razón de ser no en la realidad, sino en la virtualidad: cada vez nos hallamos más cerca de una imagen del mundo - y aquí seguimos a Heidegger - que no representa al mundo, sino el mundo comprendido como una imagen.

Habitamos una época en la que la ciencia, la técnica y todo nuestro entorno tecnológico y social están sentando las bases de un cambio radical. El prefijo «post» ha ido ganando terreno hasta convertirse en credencial indispensable para acceder a estos nuevos tiempos en los que se experimenta con las posibilidades de la plurisignificación del lenguaje, que- 
dando la imaginación al margen de los modos de proceder convencionales. La postmodernidad ha erosionado los valores de la cultura académica, abriéndose a lo popular y callejero. De la misma manera que el arte postmoderno se ha visto fascinado por la iconografía de la publicidad - para muchos Andy Warhol marca el punto de inflexión en el arte del siglo XX ya que con él surge el arte postmoderno o neovanguardista-, los drugstores, las galerías de arte, las agencias de viaje, los gabinetes de diseño, los centros de fitness y demás establecimientos afines han sido elevados a la categoría de nuevos centros culturales. ${ }^{33}$

Por otra parte, se ha roto la confianza en el ser y en las posibilidades de representarlo, tal como ya sucedió con la quiebra de la mimesis artística. Así pues, la representación del mundo se convierte en una posibilidad virtual que, lejos de oponerse a lo real, está en situación de asociarse intimamente a la textura misma de la realidad. Películas recientes como Matrix - un film de culto instantáneo, una película estandarte de toda una generación y que refleja esta época en la que impera el eclecticismo y la mezcla de géneros - oscilan entre la realidad y la virtualidad. De modo que lo virtual se articula como un mundo propio, situado junto al mundo real. Así se confirma la vigencia de esas imágenes ideales que ya no son ciencia-fición sino que se convierten en entidades propias, con una existencia virtual que es vivida, incluso, como real.

De hecho, lo virtual cambia nuestra relación con lo real $\mathrm{y}$, en consecuencia, con la idea espacio/tiempo. «El cuerpo real se virtualiza situándose en la red o sumergiéndose en los mundos virtuales, mientras que, a cambio de ello, el cuerpo en levitación virtual no deja de adquirir a veces una especie de realidad operativa». ${ }^{34}$ Gracias a esta dinámica, el cuerpo humano se diluye en una cierta intangibilidad de manera que vive rodeado por el mundo, cercado por lo visible y lo tangible, pero sumergido también en lo invisible. Probablemente resulta más atrayente vivir ese mundo de virtualidad no tangible que no un mundo de "realidades" problemáticas de difícil solución. Actitud quizás de cobardía pero que, en última instancia, expresa también un deseo y una voluntad de rechazo asumida por muchos de nuestros jóvenes: mejor navegar por un imaginario virtual que no habitar tediosamente una realidad incómoda, heredada con desgana y con escasa capacidad de ilusionar.

De ahí, quizás, la importancia de la publicidad que contribuye al desarrollo de esos imaginarios virtuales en los que da la impresión que muchos - a modo de evasiónquisieran instalarse. Así, cuando irrumpieron hace unos años esos cuerpos delgados y pálidos - que han hecho es- tragos en el mundo de la moda - muchos no entendían la emergencia de esos cuerpos que mostraban jóvenes con expresiones pasmadas y depresivas e, incluso, con un aspecto enfermizo. ¿Cuál es el significado de esa delgadez? De hecho, la delgadez ha tenido, a lo largo de la historia, un significado complejo tal como se desprende de las imágenes del éxtasis religioso, de la figura del artista hambriento o del enfermo moribundo. En cualquier caso, la pregunta no pierde vigencia. ¿Qué es lo que se quiere desear, hoy, con estos cuerpos anoréxicos? Aunque de la anorexia se ha dicho que representa una actitud propia de quien no desea crecer, también puede interpretarse como una actitud que expresa cierta rebeldía juvenil al distanciarse de los patrones culturales establecidos que, en las opulentas sociedades occidentales, exigen unos cuerpos bien alimentados. ${ }^{35}$

Por ello la anorexia también puede significar el rechazo de un cuerpo que según los cánones ha de ser robusto y que, por tanto, precisa un aporte calórico compensado y suficiente. Aunque parezca una paradoja, la salud ya no es una cosa prioritaria: lo fundamental es la imagen. En consecuencia la salud es devaluada, como ocurre en el caso de los cuerpos Danone, Sanex o Fontvella, a simples estrategias publicitarias ya que bajo unas pretendidas recomendaciones higiénicas se transmiten unos modelos 
corporales contrarios a las disposiciones de la salud pública pero que, desgraciadamente, son deseados por muchos de nuestros jóvenes.

Con todo, si se analizan detenidamente esos cuerpos tanto masculinos como femeninos, muchas veces mediatizados por las tonalidades grises de una publicidad en blanco y negro - también se puede pensar que estas figuras delgadas expresan el rechazo de buena parte de los valores (no sólo físico-corporales, sino también sociales) generalmente aceptados. «La delgadez retraída y seria que vemos en estos anuncios significa el rechazo de los códigos dominantes de interacción social, a saber lo accesible, y el rechazo de normas corporales aceptadas» ${ }^{35}$ Las normas dictan que el cuerpo debe ser alimentado convenientemente, que se ha de luchar para ser feliz, que se ha de responder a los modelos clásicos de los géneros claramente identificables, masculino o femenino. Quizás lo que sucede es que nos encontramos ante una juventud que a través de su delgadez corporal - otra manifestación de estos tiempos postmodernos - rechaza las normas sociales, como si se tratara de un juego que, en ocasiones, se hace peligroso.

Después de la lucha contra la morbosidad infantil (con su preocupación por la creación de cantinas y colonias escolares para fortalecer la salud de la infancia) nos en- contramos con una auténtica transgresión de los modelos defendidos por la modernidad médico-pedagógica que enfatizó los aspectos higiénicos que, por otra parte, no se desligaban de una dimensión moral. «El concepto de salud, una vez transformados los elementos que lo componían, sería entendido como fruto de la vinculación del cuerpo con el alma, de manera que la compostura moral sería la responsable de la salud». ${ }^{37}$ Partiendo de elementos estructurales, sociales y culturales, se estableció una total correspondencia entre el cuerpo humano y el cuerpo social. Por ende, el cuidado corporal comportaría la mejora de la sociedad, con lo que resulta lógico el éxito de la educación física - entendida desde una perspectiva higiénica y profiláctica - en el discurso pedagógico moderno. ${ }^{38}$ Los índices de robusteza que se obtenían con las fichas antropométricas de la época de entresiglos (fines del XIX y comienzos del XX) probablemente no variarían en exceso respecto los que se podrían obtener, actualmente, entre determinados grupos de nuestros jóvenes.

Algo ha cambiado substancialmente porque el culto a la belleza tísica del siglo XIX - tema típicamente romántico - ha vuelto a instalarse en esos imaginarios sobre el cuerpo. Y lo curioso del caso es que hubo que luchar denodadamente contra la tuberculosis y demás enfermedades endémicas que acecharon, y desgraciadamente continúan afectando, a la infancia. Quizás lo que ha sucedido es que el cuerpo tal como ya sucedió en los movimientos contraculturales surgidos alrededor de la fecha mítica de 1968 - se utiliza, también hoy, para manifestar un determinado tipo de rebeldía juvenil. Es sabido que aquel movimiento de protesta no fue más que la plasmación popular de una vasta revolución cultural que reportó destacadas consecuencias para el cuerpo humano. El cambio - que no afectó tanto a la política como a la cultura - supuso, a través de las pulsiones libertarias, la interiorización de nuevas prácticas y la renovación de los sistemas clásicos de educación física con la incorporación de la psicomotricidad, la danza y la expresión corporal. Sin olvidar el aerobic (con una Jane Fonda siempre joven y en forma). Fue entonces - en medio de la vorágine del 68 - cuando intelectuales como Marcuse se decantaron - y en buena medida ayudados por la crítica freudomarxista - por unos deseos no represivos, por una liberación de la represión que tenía mucho - como mínimo en apariencia - de transgresión. El eros - reivindicado desde comienzos de sigloexigía un nuevo orden corporal que liberase el cuerpo de las depravaciones del trabajo industrial y que, por ende, permitiese la expresión de un cuerpo sensual que gozase los "logros de la higiene física y la ropa agradable". ${ }^{39}$ 
Por consiguiente, los cuerpos humanos tomaban una actitud deseante favorecida por los aires de libertad. Tanto fue así que las relaciones entre los jóvenes - no hay que olvidar que en 1960 se inventó la pildora anticonceptivacambiaron profundamente. El feminismo, con sus campañas a favor de la liberación de la mujer, se expandió por doquier. Movimientos alternativos con su carga utópica como el hippismo - introdujeron los cabellos largos que desembocarían en la moda unisex. Nuevas prendas como el bikini se hacían - no sin reticencias - populares. Las piscinas y las playas, custodiadas celosamente durante años, acogieron a unos cuerpos - cuerpos expuestos al sol - que se movían al ritmo trepidante de melodías musicales cuyas letras invitaban al viaje, al veraneo, a la evasión, al ocio y a la seducción. El carpe diem postmoderno encuentra un antecedente en aquellos felices años sesenta que acabaron por imponer un estilo de vida neonómada gracias al coche utilitario $\mathrm{y}$ al turismo. El hombre - que finalmente había perdido el miedo a sumergirse en el agua - recuperaba así su capacidad anfibia popularizándose entre los escolares la natación, lo cual constituía una positiva novedad al universalizarse una práctica deportiva que había sido practicada de manera muy restringida. ${ }^{40}$

Pero a pesar de estos vientos de libertad, lo cierto es que la imperfección que se insinúa cotidianamente en el reflejo del espejo, en la mirada fiscalizadora de los otros, continúa provocando malestar. Además, el paso tiránico del tiempo potencia el mito de la eterna juventud, anatomías que gracias a la cirugía plástica mejoran cada día como el cuerpo de Cher, cuerpos congelados - como el de Walt Disney - que esperan ser reparados algún día, cuerpos que cambian el color de la piel como el de Michael Jackson, con lo cual el cuerpo acaba convirtiéndose en un significante de clase social y poder: más bellos y, pretendidamente, siempre jóvenes.

En un mundo en el que todo es fluctuante e inestable, el cuerpo se sumerge en el panestetismo dominante. El ser humano se cansa de su propio cuerpo, de parecerse las veinticuatro horas del día a sí mismo. De ahí el éxito de la moda - como expresión pública del reino de lo efímeroque favorece la aparición de diversas imágenes que van desde la presencia dura heavy) que se impone con agresividad a la delicadeza e insinuaciones de una representación blanda y suave (soft). Si tradicionalmente se ha dicho que el cuerpo es la cárcel del alma, no es menos verdad que ahora el cuerpo es el tobogán por donde se desliza el alma, o lo que es lo mismo, la "rampa de lanzamiento que catapulta hacia el paraíso de la estetización por la bella imagen". ${ }^{41}$ Todo se reduce a un simple juego de espejos, de representaciones poliédricas de un diferir constante de nuestra propia imagen: para ser uno mismo se hace imprescindible participar de ese juego de simulacros que se suceden sin cesar y que nos sitúan en una constante provisionalidad.

\section{LA RECONFIGURACIÓN \\ DEL CUERPO}

Es evidente que nuestros tiempos postmodernos (otros autores se refieren a la tardomodernidad, hipermodernidad o ultramodernidad) actúan a modo de un verdadero laboratorio donde es posible realizar todo tipo de pruebas ensayando otros órdenes simbólicos. La postmodernidad, con su crítica al etnocentrismo y a la megalomanía occidental, recupera aspectos que la racionalidad moderna, con su arrogancia dominadora y absorbente, orilló. La exposición "Las artes de África, Asia, Oceanía y las Américas", organizada recientemente por el Louvre, demuestra que Occidente se ha percatado que no es el único depositario de la imaginación y de la creación artística. Ya Lévi-Strauss vaticinó, en uno de sus artículos sobre las tribus del Pacífico, que sus obras de arte saldrían de los museos etnológicos para instalarse en los grandes centros culturales.

El proceso descolonizador de África, que tuvo lugar a partir de la década de los años sesenta y los posteriores flujos 
migratorios, ha cambiado el panorama de las ciudades que se convierten en auténticas conglomeraciones multirraciales con personas de todas las procedencias. Se ha pasado de una visión monocéntrica - articulada alrededor de un eurocentismo absorbente heredado de la Ilustración - a un planteamiento policéntrico que se configura como un espacio de aprendizaje. Este giro policéntrico no ha pasado desapercibido a los defensores de la pedagogía crítica que han destacado que el cuerpo no es simplemente el resultado de unos discursos hegemónicos sino también un lugar de lucha y de conflicto. Peter Mc Laren -desde la realidad social norteamericana - señala que cada cuerpo (afroamericano, oriental, negro, blanco, homosexual, etc.) posee una voz oculta y escondida que conviene escuchar más allá de las normativas al uso. ${ }^{42}$

El mundo actual potencia una ontología de la diferencia que se distingue de la tradicional ontología de la representación basada históricamente en el principio de identidad. La lógica de la identidad ve la diferencia como expresión de algo incontrolable, propio del exceso y del defecto. Lejos de esta posición, hoy la diferencia se inscribe en el quehacer humano: la multiplicidad y la diversidad también dan cuenta y razón de nuestra realidad más inmediata. Nos encontramos ante el nomadismo, la divergencia, el descentramiento y el constan- te diferir. Deleuze ha situado la diferencia frente a la lógica de la identidad y de la negación, lo cual ha favorecido una determinada manera de pensar el deseo. ${ }^{43}$ Sin embargo, es evidente que siempre se ha intentado congelar este juego de la différence no sólo con la defensa del principio de unidad, sino también con la formulación de teorías cerradas que han procurado cosificar la educación - y por ende, lo corporal - a fin de impedir la diseminación del significado de la pedagogía.

Si hasta hace poco la historia se ha ocupado de la normalidad, ahora parece haber llegado el momento de las diferencias de todo tipo: género, raza, lengua, edad, procedencia, etc. Al fin de cuentas, hemos entrado en un tiempo que invita a reformular todas las escrituras e, incluso, el mismo oficio de narrador porque parece que se ha perdido - como mínimo éste es el parecer de Günter Kunert - el significado del leer y del escribir. Si es cierto que todo lo construido puede ser desmantelado (ésa al fin de cuentas ha sido la tarea de la deconstrucción), no es menos verdad que también puede ser reconstruido, reconceptualizado, es decir, renovado.

Ya no hay - y felizmente, ya no podrá existir - un único modelo corporal. El hombre de raza blanca se ha percatado que ya no vive sólo en el mundo. Nos encontramos abocados al contacto, al intercambio, en fin, a una nueva cultu- ra de mestizaje en la que el cuerpo ocupa un lugar central de forma que la corporalidad constituye la auténtica condición de posibilidad para alcanzar un verdadero mundo intercultural. Los múltiples procesos de diáspora, desterritorialización, hibridación y fronterización apuntan hacia la necesidad de interacción en favor de la formación de culturas híbridas que cruzan nuevas fronteras y habitan nuevos territorios. ${ }^{44}$

Buena parte del capital humano del siglo XXI radica, precisamente, en esta visión plural de una sociedad integrada por hombres y mujeres cuyos cuerpos responden a una nueva lógica que implica algo tan simple como la aceptación del otro. La "otredad" (con todo lo que supone para la práctica pedagógico-social) parte de la corporeidad, es decir, comienza en el reconocimiento del cuerpo del otro. Con la irrupción de los vientos postmodernos se ha hecho visible una "otredad" tradicionalmente ocultada. El "otro" ha dejado de ser el objeto de deseo de una vulgar fantasía colonial. En el tránsito del siglo XIX al XX, muchos militares coloniales no entendían las razones por las cuales las tropas metropolitanas (bien alimentadas y mejor pertrechadas) se adaptaban peor a las condiciones ambientales que soldados autóctonos. La introducción de determinadas prácticas en educación física (por ejemplo, el método natural de Hébert) tiene mucho que ver con ese 
deseo de una preparación física que debía otorgar al hombre occidental la misma fortaleza física que los naturales de África o Asia. En aquellos momentos, el prestigio de la raza blanca andaba en juego ya que debía ser la más fuerte. Sólo los blancos podían correr más rápido $\mathrm{y}$ saltar más alto, tal como confirma la escenografía totalitaria de la Olimpíada de Berlín de 1936.

De hecho, la postmodernidad surge en un contexto postcolonial de modo que la cuestión ya no es blanco o negro, sino blanco y negro. Se pasa de la lógica de la exclusión a la de la integración. Es de esperar que si admitimos a "el otro", también podremos renovarnos a nosotros mismos. Sólo a partir de la aceptación de los otros cuerpos (que han dejado de ser raros y exóticos), podremos construir un mundo que dé respuestas a las exigencias de una sociedad que camina hacia un irreversible proceso de mestizaje. En definitiva, la forma de construcción de identidades implica el deseo de ser reconocido, deseo que históricamente ha sido negado a todas aquellas personas cuyos cuerpos no correspondían a los parámetros impuestos por la raza blanca.

Por ello, el cuerpo puede mediar activamente, desde un horizonte intercultural, a favor de la elaboración de nuevas cartografías que integren las distintas culturas. Frente a las tentaciones xenófobas, des- pués de las experiencias de la segregación racial (apartheid) y de las soluciones finales (Auschwitz constituye una auténtica memoria que la humanidad no puede olvidar), nos queda el recurso de otorgar al cuerpo nuevas significaciones, o lo que es lo mismo, contribuir a una reconfiguración que responda a la emergente sensibilidad postmoderna articulada en torno al principio de la diferencia.

Ahí radica, justamente, el reto que debemos abordar: reconfigurar un universo simbólico y relacional en torno al cuerpo humano que, en lugar de ser dominado, segregado, mutilado o colonizado, pueda despertar la conciencia de una nueva realidad individual y social. Quizás si empezamos a aceptar el cuerpo de los otros, acabaremos también aceptando nuestros propios cuerpos con todas sus imperfecciones y limitaciones. La imagen del otro nos puede ayudar a recomponer nuestra propia identidad personal aceptando una serie de valores emergentes (lo íntimo, lo emocional, lo sentimental, lo imaginativo), categorías olvidadas por la fría racionalidad moderna y que confirman la existencia de un verdadero giro lingüístico que ha afectado a todas las narrativas, incluso, corporales. Además, la misma distancia existente entre la realidad educativa (significado) y el discurso pedagógico (signo) permite salvar la relación entre teoría y praxis en clave metafórica. No por casualidad, la pedagogía siempre se ha movido en esta duplicidad de planos, es decir, entre la realidad y el deseo: Rousseau no quería el homme sauvauge real, sino el homme naturel hiperreal.

Probablemente sólo si apelamos a los valores de la nueva sensibilidad postmoderna se podrá amalgamar un horizonte integrador que prevenga de las tentaciones de la robotización de la vida humana. Si la historia ha estado poblada de autómatas y creaciones maquinistas, tampoco parece que vaya a desaparecer en el futuro la pasión por los humanoides. El Time de Nueva York distinguió, hace unos años, al robot con el calificativo de "hombre del año". En última instancia, la imagen del superhombre, (al fin de cuentas el actual renacimiento de Nietzsche justifica su condición de gran apóstol de la postmodernidad) parece que toma cuerpo en esos engendros que cuentan con una inteligencia computarizada que se han desligado del pasado, que no pueden olvidar nada porque para ellos la historia ya no es significativa, estando además dotados de una inteligencia artificial sin capacidad de sufrimiento y sin moral. ${ }^{45}$

Pero no hay que caer en el desánimo, ni tampoco en el pesimismo. En verdad siempre existen motivos para la esperanza y, justamente, el misterio del cuerpo humano más allá de sus analogías con máquinas, motores, robots y cyborgs- nos invita, una vez 
más, a trabajar en la configuración de nuevos imaginarios que apuesten a favor de un humanismo integrador que (malgré Foucault) permita, sin renunciar al progreso tecnológico, un mundo de posibilidades creativas. Éste es, precisamente, nuestro particular deseo para una sociedad cuyo universo corporal - y por extensión, cultural - debería caminar inexorablemente hacia el mestizaje.

\section{NotA}

${ }^{1}$ Le GOFF, J. y NORA, R, Hacer la historia. III. Objetos nuevos. Barce lona: Editorial Laia, 1980, pág. 179.

${ }^{2}$ PORTER, R., «Historia del cu erpo», en Formas de hacer Historia. Madrid: Alianza Editorial, 1993, pág. 272

${ }^{3}$ Ibidem, pág. 275.

${ }^{4}$ Entre las obras más recientes des tacamos: LAIN ENTRALGO,R, $E l$ cuerpo humano. Oriente y Grecia Antigua. Madrid: Espasa-Calpe, 1987; SOUZENELLE, A. de, Le Symbolisme du corps humaine. París: Albin Michel, 1991; ANA BUÑUEL HERAS, La construcción social del cuerpo. Prácticas gimnás ticas y nuevos modelos culturales. Madrid: Editorial de la Universidad Complutense, 1992; JACQUES ULMANN, Corps et civilisations. Education physique, médecine, sport. París: J. Vrin, 1993; JAC QUES GLEYSE, $V$ instrumentalisation du corps. Une archéologie de la rationalisation instruméntale du corps, de l'Age classique a l'époque hvpermoderne. París: L'Harmattan, 1997; AURELIO PÉREZ JIMÉNEZ y GONZALO CRUZ ANDREOTTI (Eds.), Uni dad y pluralidad del cuerpo humano. La anatomía en las culturas me diterráneas. Madrid: Ediciones Clásicas, 1999; WEISS, G., Body images. Nueva York/London: Routledge, 1999.

${ }^{5}$ ALARIO TRIGUEROS, M. T., «La imagen: un espejo distorsionador», Persona, género y educación. Salamanca: Amarú Ediciones, 1997, pp. 87-112.
${ }^{6}$ BOLUFER PERUGA, M., «Cos femení, cos social. Apunts d'historiografia sobre els sabers medies i la construcció cultural d'identitats sexuades (segles XVI-XIX)», Afers, 33/34, 1999, pp. 531-550.

${ }^{7}$ No hay que olvidar que el cuerpo femenino ha sido, y continúa siendo objeto, de diversas mutilaciones como la ablación o la infibulación que tienden a destruir parcial o to talmente la sensibilidad sexual femenina (ERLICH, M., Lafemme blessée. Essai sur les mutilations sexuelles féminines. Paris: L'Har mattan, 1986).

${ }^{8}$ BENET, V. J. y NOS, E. (Eds.), Cuerpos en serie. Castelló de la Pla na: Publicacions de la Universitat Jaume I, 1999.

${ }^{9}$ FOUCAULT, M., Microfisica del poder. Madrid: Ediciones La Pi queta, 1992, p. 104.

${ }^{10}$ VIGARELO, G., «El adiestra miento del cuerpo desde la edad de la caballería hasta la urbanidad cortesana», en M. FEHER, Frag mentos para una historia del cuerpo humano. Madrid: Taurus, 1991, par te $1 \mathrm{I}^{\mathrm{a}}$, pp. $149-197$.

${ }^{11}$ TORT, R, L'ordre et les monstres. Le débat sur l'origine des désviations anatomiques au XVIII siécle. Paris: Syllepse, 1998.

${ }^{12}$ VILANOU, C, "Winckelmann: neoclassicisme i pedagogía esté tica", en Seminari Iduna. Noves reflexions a l'entorn de l'educado estética. Publicacions de la Uni versitat de Barcelona, 1998, pp. 33-41.

${ }^{13}$ ARISTÓTELES, La Política, libro primero, capítulo IV.

${ }^{14}$ DESCARTES, El tratado del hombre. Edición a cargo de G. Quintas. Madrid: Alianza Editorial, 1990.

15 DAMASIO, A.R., El error de Descartes. Barcelona: Crítica, 1996.

${ }^{16}$ LEIBNIZ, W. G., Monadología, 64.

${ }^{17}$ GIMÉNEZ CABALLERO, E., Hércules jugando a los dados. Madrid: Ediciones La Nave, 1928.

${ }^{18}$ LA METTRIE, Obra Filosófica. Madrid: Editora Nacional, 1983, pág. 250.

${ }^{19}$ ARACIL, A., Juego y artificio. Autómatas y otras ficciones en la cultura del Renacimiento a la

\section{Ilustración. Madrid: Cátedra, 1998.}

${ }^{20}$ Los ready-made son objetos normales de la vida cotidiana (una rueda de bicicletas, un taburete, una jaula). Se trata de objetos anónimos que, a pesar de su aparente inu tilidad, buscan la provocación y la ironía. El primer ready-made co nocido data de 1913 y consistía en la yuxtaposición de una rueda de bicicleta y un taburete, pero el primero que se expuso fue Fontaine (1917) que no era otra cosa que un urinario.

${ }^{21}$ Entre la amplia bibliografía exis tente sobre el particular, citamos: GEDULD, H. M. y GOTTESMAN, R. (Ed.), Robots. New York: Graphic Society, 1978 y LOGSDON, T., Robots: una revolución. Barcelona: Orbis, 1987 ( $3^{\mathrm{a}}$ ed.).

${ }^{22}$ SERRES, M., Feux et signaux de brume: Zola. París: Grasset, 1975. También sobre este tema: RABINBACH, A., The human motor: Energy, fatigue and the origins of modernity. Basic Books, 1990.

${ }^{23}$ DÍAZ CUYAS, J. (Coordinador), Cuerpos a motor. Las Palmas de Gran Canaria: Centro Atlántico de Arte Moderno, 1997, pág. 160.

${ }^{24}$ En marzo de 1928, Salvador Dalí -junto a Lluis Montanyá y Sebastiá Gasch- publicaron el Manifest Groe que sería tildado de futurista y en el que expresaban su entusiasmo por los objetos industriales, por el de porte, el nudismo, el cine y la fotografía. Este manifiesto fue reproducido en castellano por Gallo, la revista que editaba Federico García Lorca en Granada.

${ }^{25}$ TUSQUETS, J., Tarzán contra Robot. El neonomadismo y el neosedentarismo protagonistas de la crisis contemporánea. Barcelona: Oikos-Tau, 1986.

${ }^{26}$ Por su significación destacamos la exposición Post Human. Nuevas for mas de la figuración en el arte contemporáneo que circuló, durante el año 1992, por diferentes pases de Eu ropa. Para un amplio comentario sobre lamisma: OLIVARES, R., Lápiz, núm. 93, mayo 1993, pp. 24-28.

${ }^{27}$ DE LA PUENTE MARTORELL, J. M.., "El cyborg, la monia, el arquitecto. La explosión de los modelos antropocéntricos en ar quitectura", Congrés Internacional: El Futur de l'Arquitecte (Ment, lerritori, societat), Barcelona: UPC, 2000, pág. 60 
${ }^{28}$ HARAWAY, D. J., Ciencia, cyborgs y mujeres. La reinvención de la naturaleza. Madrid: Cátedra, 1995.

${ }^{29}$ GIANNETTI, C, «Cyborg no tiene género. Reflexiones sobre la mujer, la ciencia, las nuevas tec nologías y el ciberespacio», en Sólo para tus ojos; el factor feminista en relación a las artes visuales. Donostia: Arteleku, 1997, pp. 15-20.

${ }^{30}$ Con relación a la creación cinema tográfica de este tipo de engendros, véase: DEL TESO, B., «Todo ser tiene su rostro, nuestro rostro", Hombres y máquinas. Realidad y representación. San Sebastián: Arteleku, 1998, pp. 99-114.

${ }^{31}$ Destacar aquí la exposición «Cronos» del fotógrafo Pere Formiguera que presentó en el Centre d'Art Santa Mónica de Barcelona, durante la primavera del año 2000 , el resumen de un trabajo realizado a lo largo de diez años. De 1991 al 2000, tomó cada mes una fotografia a 32 personas de diferentes edades. Cada uno elegía ser fotografiado desnudo de medio cuerpo, de cuerpo entero o sólo la cabeza. El proyecto logró reunir miles de fotografías que registraron mes a mes el proceso, a lo largo de una década, del cre cimiento o del envejecimiento humano. La muestra de la ex posición recoge unas 600 imágenes que corresponden a varios adultos y adolescentes.

${ }^{32}$ OLIVARES, R., «En cuerpo y alma», Lápiz, XVII, núm. 139/140, enero-febrero 1998, pág. 77.

${ }^{33}$ Con relación al tema de la post modernidad, véase: VILANOU, C, «Danzas y contradanzas de la modernidad: hacia un nuevo imaginario cultural y pedagógico», Alternativas (Universidad de San Luis, Argentina), núm. 16, octubre de 1999, pp. 17-44.

${ }^{34}$ QUÉAU, Ph., «La presencia del espíritu», Revista de Occidente, núm. 206, julio 1998, pág. 53.

${ }^{35}$ Por el contrario, la delgadez apa rece en la mayor parte del mundo como una consecuencia del hambre y de la escasez de alimentos a que se ve sometida la humanidad. Des graciadamente, esa delgadez auténtica piedra de escándalo- se diluye en una serie de imágenes informativas que generan impa sibilidad e indiferencia.

${ }^{36}$ WALLERSTEIN, K., «La del gadez y otras negaciones en la publicidad de la moda contempo ránea», Debate Feminista (México), núm. 19, abril 1999, pp. 182.

${ }^{37}$ RUIZ SOMAVILLA, M. J., «El cuerpo limpio». Análisis de las prácticas higiénicas en la España del mundo moderno. Málaga: Universidad de Málaga, 1993, pág. 132.

${ }^{38}$ RAUCH, A., Le souci du corps. Histoire hygiéne en éducation physique. París: P.U.F., 1983. Tam bién puede consultarse el clásico estudio de VIGARELLo, G., Le prope et le sale. L'hygiéne du corps depuis le Moyen age. París: Seuil, 1985.

${ }^{39}$ MARCUSE, H., Eros y civi lización. Barcelona: Seix Barral, 1976, pág. 12.

${ }^{40}$ Aunque los humanistas del Re nacimiento (por ejemplo, Rabelais) recomendaban la natación, su apren- dizaje ha constituido históricamente una empresa difícil. En 1538 Nicolás Wynmann publicó el primer tratado de natación con el título de $\mathrm{Co}$ lymbetes o el arte de nadar. Todavía en el siglo XIX - e incluso en el XXproliferó este tipo de literatura encaminado a fomentar las capacidades y hábitos natatorios.

${ }^{41}$ SALABERT, P, "Panestetismo", Manía, núm. 1, pág. 28.

${ }^{42}$ DE ALBA, A. (Compiladora), Postmodernidad y educación. Mé xico: CESU/Porrúa, 1995.

${ }^{43}$ FERREIRA SANTOS, L., Pensar o Desejo. Freud, Girard e Deleuze. Braga: Universidade do Minho. Ins tituto de Educacao e Psicología, 1997.

${ }^{44}$ Con relación a este tema, véase: JARAUTA, F. (Ed.). Nuevas fronte ras/Nuevos territorios. San Sebastián: Arteleku, 1996, en especial el trabajo de Kewin Power "El mestizaje: la identidad de los noventa" (pp.153209).

${ }^{45} \mathrm{La}$ mayor atracción de la ex posición «Sieben Hügel» (Siete colinas. Imágenes y signos del siglo XXI), abierta desde la primavera hasta el otoño del año 2000 , en el Centro Martin Gropius de Berlín, fue el robot Honda P3, considerado el humanoide más avanzado del mundo. Construido por la mul tinacional automovilística japonesa, que trabajó catorce años en el proyecto, el P3 es capaz de subir y bajar escaleras, moverse en sentido lateral, abrir puertas, transportar ob jetos, estrechar manos $y$ otras habilidades que tendrán aplicaciones domésticas. Su altura es de 1,60 metros y pesa 130 Kilogramos. 